\title{
BMJ Open Hazardous alcohol consumption among university students in Ireland: a cross-sectional study
}

\author{
Martin P Davoren, ${ }^{1}$ Frances Shiely, ${ }^{1}$ Michael Byrne, ${ }^{2}$ Ivan J Perry ${ }^{1}$
}

To cite: Davoren MP, Shiely F, Byrne M, et al. Hazardous alcohol consumption among university students in Ireland: a cross-sectional study. BMJ Open 2015;5: e006045. doi:10.1136/ bmjopen-2014-006045

- Prepublication history for this paper is available online. To view these files please visit the journal online (http://dx.doi.org/10.1136/ bmjopen-2014-006045).

Received 5 July 2014 Revised 3 October 2014 Accepted 6 October 2014

\section{CrossMark}

\footnotetext{
${ }^{1}$ Department of Epidemiology and Public Health, University College Cork, Cork, Ireland ${ }^{2}$ Student Health Department, University College Cork, Cork, Ireland
}

Correspondence to Martin P Davoren; m.davoren@ucc.ie

\section{ABSTRACT}

Objective: There is considerable evidence of a cultural shift towards heavier alcohol consumption among university students, especially women. The aim of this study is to investigate the prevalence and correlates of hazardous alcohol consumption (HAC) among university students with particular reference to gender and to compare different modes of data collection in this population.

Setting: A large Irish university.

Design: A cross-sectional study using a classroom distributed paper questionnaire.

Participants: A total of 2275 undergraduates completed the classroom survey, $84 \%$ of those in class and $51 \%$ of those registered for the relevant module.

Main outcome measures: Prevalence of HAC measured using the Alcohol Use Disorders Identification Test for Consumption (AUDIT-C) and the proportion of university students reporting 1 or more of 13 adverse consequences linked to HAC. HAC was defined as an AUDIT-C score of 6 or more among males and 5 or more among females.

Results: In the classroom sample, $66.4 \%(95 \% \mathrm{Cl} 64.4$ to 68.3 ) reported HAC $(65.2 \%$ men and $67.3 \%$ women). In women, $57.4 \%$ met HAC thresholds for men. Similar patterns of adverse consequences were observed among men and women. Students with a hazardous

consumption pattern were more likely to report smoking, illicit drug use and being sexually active.

Conclusions: The findings highlight the high prevalence of HAC among university students relative to the general population. Public policy measures require review to tackle the short-term and long-term risks to physical, mental and social health and well-being.

\section{INTRODUCTION}

Problem alcohol use is an ongoing, worldwide phenomenon of considerable concern. ${ }^{1-4}$ Ireland displays a unique relationship with alcohol with significantly higher intakes than the Organisation for Economic Co-operation and Development (OECD) average, ${ }^{5}$ the $\mathrm{USA}^{6}$ and the UK. ${ }^{7}$ In addition, the Eurobarometer study notes that Irish adults report hazardous drinking more frequently than any other EU country. ${ }^{2}$ Recently, it was reported that $54 \%$ of

\section{Strengths and limitations of this study}

- The current study employed standardised methods for the measurement of hazardous alcohol consumption and a rigorous probability proportion to size sampling strategy for the classroom-based survey.

- In regard to gender and course of study, the study participants were representative of the university undergraduate student population from which they were sampled.

- The overall response rate, defined in terms of students registered for specific modules, was $51 \%$. However, the response rate for those in attendance at lectures was $84 \%$. There was over-representation of first year students and under-representation of fourth year students in the sample.

- Although the response rate was low, it is similar to that achieved in major international studies of student alcohol consumption. It should also be noted that the majority of non-respondents were students absent from class during the survey. The latter group of students is unlikely to have a more favourable pattern of alcohol consumption than that observed in this study. Thus, this study may be regarded as reporting the lower bound estimates of hazardous alcohol consumption in Irish university students.

Irish adults reported hazardous alcohol consumption (HAC). ${ }^{8}$ University students represent a unique subsection of society. ${ }^{9}$ In this environment, there is a culture of $\mathrm{HAC},{ }^{10}$ defined as "a pattern of alcohol consumption that increases the risk of harmful consequences for the user or others". ${ }^{11}$ The findings from the 2002 to 2003 College Lifestyle Attitudinal National Survey in Ireland indicated that at least 60 in every 100 drinking occasions among students involved HAC. ${ }^{10}$ This suggests that HAC is a cultural norm among university students in Ireland. Previous research using the Alcohol Use Disorders Identification Test for Consumption (AUDIT-C) scale has reported lower levels of hazardous consumption among non-university peers $(36 \%)^{12}$ and the general population $(54 \%){ }^{8}$ 
In a number of countries, hazardous drinking has been identified as the number one substance abuse problem during university life. ${ }^{10}{ }^{13-15}$ A comprehensive review of drinking habits in European universities found a range of studies suggesting that hazardous levels of alcohol consumption were associated with increased levels of smoking and drug use. ${ }^{16}$ In Ireland, the College Lifestyle Attitudinal National survey in Ireland noted high levels of alcohol consumption and other risktaking behaviours among students. ${ }^{10}$ However, these data were collected over 10 years ago and there is a clear need for contemporary Irish data to guide public policy response to this issue.

Differences in the volume of alcohol consumed by women and men in universities have been reported in some studies. ${ }^{1} 1014{ }^{16-20}$ Harrell and Karim ${ }^{18}$ found that male students reported significantly higher alcohol intakes than their female peers, a result mirrored in other studies. ${ }^{19}{ }^{20}$ More recently, international research has noted a shift in alcohol consumption among university students with some studies reporting similar patterns of hazardous drinking in men and women. ${ }^{21} \mathrm{~A}$ review investigating the consequences of alcohol misuse noted that gender differences in relation to the adverse consequences of alcohol consumption were also beginning to decrease. ${ }^{22}$ For instance, Hoeppner $e t a l^{23}$ found that females were more likely to exceed their recommended weekly alcohol allowance than their male counterparts.

Thus, the aim of this study was to investigate the prevalence of HAC and the adverse consequences associated with its use among university students in Ireland, with particular reference to gender differences.

\section{METHODS AND PARTICIPANTS}

Undergraduate students attending one large university in Ireland, University College Cork (UCC), were eligible for inclusion in the classroom-based study which was focused on health and lifestyle with particular reference to alcohol consumption. Students were sampled at degree programme level using probability proportional to size (PPS) sampling. We estimated the required sample size at 2686 students, based on an undergraduate student population of 12475 , a required precision of $1.5 \%$ and an expected prevalence of HAC of $73 \%$, based on an earlier unpublished masters dissertation. ${ }^{24}$ Lecturers or module coordinators were contacted to request permission to distribute and collect questionnaires during $15 \mathrm{~min}$ of lecture time on a date convenient to them between 12 March and 23 March 2012. Students were briefed orally and in writing (on the front sheet of the questionnaire) on the aims and objectives of the study including details of the confidential, anonymous and voluntary nature of the exercise. Participating in the research was presumed to imply consent. To enhance the response rate, the distribution of questionnaires was avoided on Mondays and Fridays due to Irish student social and recreational patterns.
Of the lecturers/module coordinators approached to facilitate the study, $94.3 \%$ agreed to cooperate. A total, 2332 students completed this face-to-face lecture theatrebased survey; 57 students were subsequently identified as postgraduate students and were excluded from the analyses. Thus, data are available on a total of 2275 undergraduates with a response rate of $84 \%$ for those attending class on the day of survey and $51 \%$ of those registered for the specific modules. The gender and the degree programme profiles of the sample collected were broadly similar to those registered with the university; $63.1 \%$ of the sample were women versus $56 \%$ for the university, $39.7 \%$ were registered with the College of Arts, Celtic Studies and Social Sciences (university 33\%), $20.1 \%$ with Business and Law (university 21\%), 24.6\% with Science, Engineering and Food Science (university 27\%) and $14.2 \%$ with Medicine and Health (university $19 \%$ ). However, with regard to year in college, there was an oversampling of first years $(46.8 \%$ vs $32.1 \%)$ and undersampling of fourth years $(7.7 \%$ vs $16.7 \%)$.

As an incentive, participants were invited to enter a draw to win a tablet computer following survey completion. As completion was anonymous, each student was advised to send an email with their name and email address to enter the prize draw. Details of how to enter were included on their postquestionnaire information sheet which was handed out in the lecture theatre. This postquestionnaire information sheet also included contact information to different websites and institutions offering help and advice on alcohol-related issues.

\section{Questionnaire}

A total of 49 questions were included in the questionnaire, which was based on previously validated instruments, including the AUDIT-C, ${ }^{25}$ the Warwick Edinburgh Mental Well-being scale (WEMWBS) ${ }^{26}$ and the International Physical Activity Questionnaire (IPAQ). ${ }^{27}$ In addition, questions on smoking status, ${ }^{28}$ drug use, ${ }^{29}$ sexual practice and activity, ${ }^{10}$ diet and self-reported height and weight ${ }^{29}$ were taken from the national survey on health and lifestyle in Ireland ${ }^{29}$ and previous university research. ${ }^{10}{ }^{28}$ All of these instruments have previously shown reliability and validity among a student population. ${ }^{30}$ It took approximately $12 \mathrm{~min}$ to complete the paper-based questionnaire.

HAC was estimated using the AUDIT-C developed by the $\mathrm{WHO}^{11}$ to identify hazardous patterns of alcohol consumption. The AUDIT-C takes the first three questions of the AUDIT questionnaire. These questions focus on the frequency of consumption, the number of units consumed and the number of binge drinking occasions. The guidelines on safe alcohol consumption in women are lower than those for men, reflecting their increased vulnerability to alcohol-related harm. ${ }^{31}$ In this study, therefore, HAC was defined as an AUDIT-C score of 6 or more among males and 5 or more among females. This instrument has demonstrated high 
sensitivity and specificity among a population of young adults aged between 18 and 20 years. ${ }^{25} 3233$

Body mass index (BMI) was estimated from self-reported height and weight with normal weight, overweight and obesity defined as BMI of 20-24.99, 25-29.99 and $\geq 30 \mathrm{~kg} / \mathrm{m}^{2}$, respectively. Physical activity was coded as low, moderate and high using the standard IPAQ protocol. ${ }^{27}$ WEMWBS scores were divided into categories of mental well-being as defined by Braunholtz et al. ${ }^{34}$ Below average mental well-being was defined as a WEMWBS score of more than $1 \mathrm{SD}$ below the mean, average mental wellbeing was within $1 \mathrm{SD}$ of the mean and above average mental well-being was over 1 SD above the mean. ${ }^{35}$

\section{Data management and statistical analysis}

The questionnaire data were scanned, checked and verified using TeleForm TM scanning processes. The estimated error rate for data entry was $0.06 \%$ based on manual checking of a $10 \%$ sample of all scanned questionnaires. All data were analysed using IBM SPSS Statistics V.20. Univariate and multivariate logistic regression analyses were undertaken to investigate factors associated with HAC separately in men and women.

\section{RESULTS}

\section{HAC in the classroom study sample}

The prevalence of HAC was similar in men $(65.2 \%)$ and women $(67.3 \%)$. In women, $57.4 \%$ met HAC thresholds for men. Only $8.4 \%$ of men and $5.8 \%$ of women were non-drinkers. Approximately $17 \%$ of men and $5 \%$ of women had an AUDIT-C score of 10 or higher. This equates to consuming more than six units of alcohol at least four times per week and in some cases daily. The prevalence of HAC by age, sociodemographic variables and lifestyle factors is presented in table 1, stratified by gender. Broadly similar trends were observed in univariate analyses in men and women with higher prevalence of HAC associated with later years in college, studying Business or Law, not owning a house, current smoking, illicit drug use and being sexually active. HAC was associated with above average mental well-being in men but not in women in these univariate analyses.

\section{Multivariate analysis}

Controlling for age only, males ( $\mathrm{OR}=2.26,95 \%$ CI 1.46 to 3.49; $\mathrm{p}<0.001)$ and females $(\mathrm{OR}=2.12,95 \%$ CI 1.44 to 3.14 ; $\mathrm{p}<0.001)$ studying Law and Business were over twice as likely to report HAC as their peers studying Science and Engineering. Among males, those in third year were 56\% more likely to report HAC $(\mathrm{OR}=1.56,95 \%$ CI 1.02 to 2.41 ; $\mathrm{p}<0.001$ ), while among females those in fourth year were $80 \%$ more likely to report HAC than their counterparts in first year (OR=1.80, 95\% CI 1.14 to 2.86). Male smokers were more than twice as likely to report HAC while female smokers were more than three times as likely to report HAC compared with their non-smoking peers. In men and women, those reporting illicit drug use were over twice as likely to report HAC. Males reporting 1-3, 4-5 and $6+$ lifetime sexual partner were 4, 5 and 6 times more likely to report HAC than those reporting no sexual partners. For females, the ORs increased threefold, fivefold and sevenfold for the same categories.

In further analyses controlling for age, course of study, accommodation type and college year, males $(\mathrm{OR}=2.33$, 95\% CI 1.52 to 3.26; $\mathrm{p}=0.001)$ and females $(\mathrm{OR}=2.11,95 \%$ CI 1.51 to $2.96 ; \mathrm{p}<0.001)$ who reported illicit drug use were more likely to report HAC. Among females, current smokers were almost twice as likely to report HAC compared with their non-smoking female peers $(\mathrm{OR}=1.95$, 95\% CI 1.36 to $2.81 ; \mathrm{p}<0.001)$. However, in these adjusted analyses, the association of smoking with HAC in males was attenuated. The association between HAC and number of sexual partners was also somewhat attenuated in these adjusted analyses but remained highly significant.

The final model was adjusted for other significant factors from the age adjusted model. The model observes that being a house owner is negatively associated with HAC for both males and females while being in second year is negatively associated for males. In contrast, studying Law and Business was positively associated with HAC. Males and females reporting one or more sexual partners or illicit drug use were also positively associated with HAC as were females who reported smoking. These results are shown in table 2.

\section{Adverse consequences}

The pattern and frequency of adverse consequences of alcohol consumption was broadly similar in men and women. However, men were more likely to report getting into a fight $(\mathrm{p}=0.001)$ and having a one-night stand $(p<0.001)$ than women. No significant differences were found for other secondhand effects. Table 3 shows the proportion of students reporting 1 or more of 13 adverse consequences of alcohol consumption. Over $70 \%$ of men with an HAC pattern reported regretting something they had said or done due to their alcohol consumption. Over $60 \%$ reported missing days from work or college due to their alcohol consumption, affecting academic performance and future prospects. In men, stark differences were observed between hazardous and non-hazardous alcohol consumers in relation to unintended $(19.2 \%$ vs $2.8 \%)$ and unprotected sex $(16.8 \%$ vs $3.3 \%)$. Similarly, in women, the burden of adverse consequences was substantially greater among hazardous drinkers than their non-hazardous peers, with $73 \%$ regretting something they said or did after drinking compared with $35.5 \%$ of their peers. Approximately, $17 \%$ of female hazardous drinkers reported unintended sex while $13.8 \%$ reported unprotected sex because of their drinking compared with $3.5 \%$ and $3.8 \%$, respectively, among their peers.

\section{DISCUSSION}

These findings highlight the extremely high prevalence of HAC $(66.4 \%)$ relative to the general population, 
Table 1 Prevalence of hazardous alcohol consumption by gender, age, sociodemographic and lifestyle factors

\begin{tabular}{|c|c|c|c|c|}
\hline & Men $(\mathrm{N}=830(36.9 \%))$ & p Value & Women ( $\mathrm{N}=1420$ (63.1\%)) & p Value \\
\hline \multicolumn{5}{|l|}{ All } \\
\hline & $541(65.2 \%)$ & & $956(67.3 \%)$ & \\
\hline \multicolumn{5}{|l|}{ Age } \\
\hline$\leq 18$ & $72(67.9 \%)$ & 0.003 & $138(74.2 \%)$ & 0.04 \\
\hline 19 & $190(70.1 \%)$ & & $290(69.2 \%)$ & \\
\hline 20 & $101(66.9 \%)$ & & $214(68.6 \%)$ & \\
\hline 21 & $71(70.3 \%)$ & & $139(66.5 \%)$ & \\
\hline $22+$ & $100(53.5 \%)$ & & $159(60.9 \%)$ & \\
\hline \multicolumn{5}{|l|}{ Course of study } \\
\hline Science/Engineering/Food Science & $159(62.6 \%)$ & 0.001 & $192(65.1 \%)$ & $<0.001$ \\
\hline Arts/Social Science/Education & $182(59.5 \%)$ & & $367(63.4 \%)$ & \\
\hline Law and Business & $145(77.5 \%)$ & & $204(79.4 \%)$ & \\
\hline Medicine and Health & $38(61.3 \%)$ & & $175(68.4 \%)$ & \\
\hline Other & $11(78.6 \%)$ & & $13(65 \%)$ & \\
\hline \multicolumn{5}{|l|}{ Year in college } \\
\hline First & $286(65.0 \%)$ & 0.03 & $402(65.6 \%)$ & 0.046 \\
\hline Second & $112(58.0 \%)$ & & $299(70.0 \%)$ & \\
\hline Third & $104(72.7 \%)$ & & $165(63.2 \%)$ & \\
\hline Fourth & $39(72.2 \%)$ & & $90(75.6 \%)$ & \\
\hline \multicolumn{5}{|l|}{ Accommodation } \\
\hline Campus accommodation & $49(70.0 \%)$ & 0.005 & $140(67.6 \%)$ & $<0.001$ \\
\hline Rented house/flat & $209(67.0 \%)$ & & $410(70.1 \%)$ & \\
\hline Parents' house & $256(65.6 \%)$ & & $381(67.0 \%)$ & \\
\hline House owner & $20(41.7 \%)$ & & $19(38.0 \%)$ & \\
\hline \multicolumn{5}{|l|}{ BMI } \\
\hline Normal weight & $355(65.7 \%)$ & 0.97 & $630(66.7 \%)$ & 0.96 \\
\hline Overweight/obese & $145(65.9 \%)$ & & $135(66.5 \%)$ & \\
\hline \multicolumn{5}{|l|}{ Physical activity } \\
\hline Low & $162(66.1 \%)$ & 0.83 & $295(65.7 \%)$ & 0.07 \\
\hline Moderate & $230(65.7 \%)$ & & $374(65.4 \%)$ & \\
\hline High & $140(63.6 \%)$ & & $269(72.1 \%)$ & \\
\hline \multicolumn{5}{|l|}{ Mental well-being (WEMWBS) } \\
\hline Below average well-being & $79(57.7 \%)$ & 0.02 & $169(65.3 \%)$ & 0.64 \\
\hline Average well-being & $372(65.0 \%)$ & & $660(68.1 \%)$ & \\
\hline Above average well-being & $90(74.4 \%)$ & & $127(66.1 \%)$ & \\
\hline \multicolumn{5}{|l|}{ No. of sexual partners } \\
\hline None & $72(41.6 \%)$ & $<0.001$ & $120(45.8 \%)$ & $<0.001$ \\
\hline $1-3$ & $246(72.4 \%)$ & & $479(69.8 \%)$ & \\
\hline $4-5$ & 67 (76.1\%) & & $146(76.8 \%)$ & \\
\hline $6+$ & $121(68.4 \%)$ & & 147 (79.9\%) & \\
\hline \multicolumn{5}{|l|}{ Smoker } \\
\hline Yes & $163(73.4 \%)$ & 0.002 & $292(81.3 \%)$ & $<0.001$ \\
\hline No & $361(61.8 \%)$ & & $647(62.7 \%)$ & \\
\hline \multicolumn{5}{|l|}{ Illicit drug user } \\
\hline Yes & 251 (76.3\%) & $<0.001$ & $302(81.6 \%)$ & $<0.001$ \\
\hline No & $290(57.9 \%)$ & & $654(62.3 \%)$ & \\
\hline
\end{tabular}

the burden of related adverse consequences and the narrowing of the gender gap among students in a large Irish university. ${ }^{24}$ Almost two-thirds of respondents reported HAC (65.2\% men and $67.3 \%$ women), and in women, $57.4 \%$ of the sample meet the current HAC thresholds for men. It has been suggested that the threshold for hazardous drinking is too low. ${ }^{36}$ However, it is based on the well-defined biological and behavioural effects of alcohol. ${ }^{11}$ In the context of the present study, it should also be noted that within the large group of hazardous drinkers, over one-quarter of hazardous drinkers were consuming more than six units of alcohol (binge drinking) at least 2-3 times per week and in some cases daily.

Alcohol consumption has been noted as the number one public health problem facing universities. ${ }^{37}$ Previously, significant differences were observed among male and female students in the College Lifestyle and Attitudinal National (CLAN) survey ${ }^{10}$ In a more recent study from University College Cork using the same 
Table 2 Multivariate logistic regression: risk factors associated with male and female hazardous alcohol consumption

\begin{tabular}{|c|c|c|c|c|c|c|c|c|c|c|c|c|}
\hline & \multicolumn{6}{|l|}{ Male } & \multicolumn{6}{|c|}{ Female } \\
\hline & \multicolumn{2}{|c|}{ Age adjusted } & \multicolumn{2}{|c|}{$\begin{array}{l}\text { Multivariate } \\
\text { analysis* }\end{array}$} & \multicolumn{2}{|c|}{$\begin{array}{l}\text { Multivariate } \\
\text { analysis } \dagger\end{array}$} & \multicolumn{2}{|c|}{ Age adjusted } & \multicolumn{2}{|c|}{$\begin{array}{l}\text { Multivariate } \\
\text { analysis }{ }^{*}\end{array}$} & \multirow{2}{*}{\multicolumn{2}{|c|}{$\begin{array}{l}\text { Multivariate } \\
\text { analysis } †\end{array}$}} \\
\hline & $\overline{\text { OR }}$ & $95 \% \mathrm{Cl}$ & $\overline{\text { OR }}$ & $95 \% \mathrm{Cl}$ & OR & $95 \% \mathrm{Cl}$ & $\overline{\text { OR }}$ & $95 \% \mathrm{Cl}$ & $\overline{\text { OR }}$ & $95 \% \mathrm{Cl}$ & & \\
\hline \multicolumn{13}{|l|}{ Course of study } \\
\hline Science/Engineering/Food Science & 1.00 & & 1.00 & & 1.00 & & 1.00 & & 1.00 & & 1.00 & \\
\hline Arts/Social Science/Education & 1.07 & 0.75 to 1.53 & 0.62 & 0.41 to 0.94 & 0.75 & 0.49 to 1.15 & 1.03 & 0.76 to 1.39 & 0.82 & 0.59 to 1.15 & 0.87 & 0.62 to 1.23 \\
\hline Law and Business & 2.26 & 1.46 to 3.49 & 2.52 & 1.54 to 4.11 & 2.81 & 1.70 to 4.63 & 2.12 & 1.44 to 3.14 & 2.18 & 1.39 to 3.42 & 2.17 & 1.37 to 3.42 \\
\hline Medicine and Health & 1.14 & 0.63 to 2.06 & 1.01 & 0.52 to 1.95 & 1.01 & 0.52 to 1.96 & 1.20 & 0.84 to 1.73 & 1.18 & 0.79 to 1.77 & 1.22 & 0.81 to 1.84 \\
\hline Other & 2.49 & 0.66 to 9.36 & 1.15 & 0.29 to 4.68 & 1.46 & 0.34 to 6.23 & 1.09 & 0.42 to 2.85 & 0.85 & 0.31 to 2.33 & 0.99 & 0.36 to 2.71 \\
\hline \multicolumn{13}{|c|}{ ( } \\
\hline First & 1.00 & & 1.00 & & 1.00 & & 1.00 & & 1.00 & & 1.00 & \\
\hline Second & 0.86 & 0.60 to 1.24 & 0.54 & 0.35 to 0.82 & 0.55 & 0.35 to 0.85 & 1.28 & 0.98 to 1.69 & 0.91 & 0.66 to 1.25 & 0.94 & 0.68 to 1.30 \\
\hline Third & 1.56 & 1.02 to 2.41 & 1.24 & 0.73 to 2.11 & 1.21 & 0.07 to 2.10 & 0.95 & 0.70 to 1.30 & 0.82 & 0.56 to 1.19 & 0.91 & 0.62 to 1.34 \\
\hline Fourth & 1.57 & 0.83 to 2.98 & 0.66 & 0.32 to 1.36 & 0.67 & 0.31 to 1.45 & 1.80 & 1.14 to 2.86 & 1.07 & 0.60 to 1.88 & 1.35 & 0.75 to 2.42 \\
\hline \multicolumn{13}{|l|}{ Accommodation } \\
\hline Campus accommodation & 1.00 & & 1.00 & & 1.00 & & 1.00 & & & & 1.00 & \\
\hline Rented house/apartment & 1.47 & 0.53 to 4.08 & 0.60 & 0.30 to 1.19 & 0.57 & 0.28 to 1.19 & 1.32 & 0.93 to 1.88 & 0.86 & 0.57 to 1.30 & 1.02 & 0.67 to 1.55 \\
\hline Parents' house & 0.91 & 0.52 to 1.59 & 0.52 & 0.27 to 1.01 & 0.50 & 0.25 to 1.00 & 1.06 & 0.75 to 1.50 & 0.78 & 0.53 to 1.17 & 0.84 & 0.56 to 1.26 \\
\hline House owner & 1.47 & 0.47 to 4.08 & 0.17 & 0.07 to 0.43 & 0.16 & 0.06 to 0.43 & 0.95 & 0.92 to 0.98 & 0.19 & 0.09 to 0.40 & 0.23 & 0.11 to 0.51 \\
\hline \multicolumn{13}{|c|}{ (2) - } \\
\hline Normal weight & 1.00 & & 1.00 & & 1.00 & & 1.00 & & 1.00 & & 1.00 & \\
\hline Overweight/obese & 1.30 & 0.91 to 1.87 & 1.12 & 0.76 to 1.66 & 1.08 & 0.73 to 1.59 & 1.10 & 0.78 to 1.54 & 1.07 & 0.74 to 1.53 & 1.05 & 0.73 to 1.51 \\
\hline \multicolumn{13}{|l|}{ Physical activity } \\
\hline Low & 1.00 & & 1.00 & & 1.00 & & 1.00 & & 1.00 & & 1.00 & \\
\hline Moderate & 0.94 & 0.66 to 1.34 & 1.25 & 0.79 to 1.98 & 1.18 & 0.72 to 1.92 & 0.99 & 0.76 to 1.30 & 0.88 & 0.65 to 1.20 & 0.88 & 0.63 to 1.24 \\
\hline High & 0.91 & 0.61 to 1.34 & 1.05 & 0.70 to 1.59 & 0.92 & 0.60 to 1.42 & 1.12 & 1.04 to 1.93 & 1.23 & 0.87 to 1.74 & 1.36 & 0.93 to 1.99 \\
\hline \multicolumn{13}{|l|}{ Number of sexual partners } \\
\hline None & 1.00 & & 1.00 & & & & 1.00 & & 1.00 & & 1.00 & \\
\hline $1-3$ & 4.12 & 2.78 to 6.08 & 3.58 & 2.39 to 5.49 & 3.53 & 2.26 to 5.53 & 3.09 & 2.28 to 4.15 & 2.58 & 1.87 to 3.55 & 2.67 & 1.87 to 3.81 \\
\hline $4-5$ & 5.70 & 3.13 to 10.36 & 4.25 & 2.22 to 8.16 & 4.39 & 2.14 to 8.71 & 5.36 & 3.45 to 8.35 & 3.21 & 2.00 to 5.13 & 3.08 & 1.83 to 5.19 \\
\hline 6 or more & 6.90 & 1.04 to 11.77 & 3.83 & 2.18 to 6.73 & 3.88 & 2.14 to 7.01 & 7.40 & 4.58 to 12.0 & 3.14 & 1.91 to 5.17 & 3.35 & 1.97 to 5.72 \\
\hline \multicolumn{13}{|c|}{ (1) } \\
\hline No & 1.00 & & 1.00 & & 1.00 & & 1.00 & & 1.00 & & 1.00 & \\
\hline Yes & 2.70 & 1.81 to 4.04 & 1.06 & 0.68 to 1.66 & 0.86 & 0.54 to 1.37 & 3.38 & 2.44 to 4.68 & 1.95 & 1.36 to 2.81 & 1.99 & 1.35 to 2.93 \\
\hline \multicolumn{13}{|l|}{ Illicit drug user } \\
\hline No & 1.00 & & 1.00 & & 1.00 & & 1.00 & & 1.00 & & 1.00 & \\
\hline Yes & 2.33 & 1.70 to 3.21 & 2.23 & 1.52 to 3.26 & 2.43 & 1.63 to 3.63 & 2.59 & 1.93 to 3.47 & 2.11 & 1.51 to 2.96 & 1.90 & 1.33 to 2.71 \\
\hline
\end{tabular}




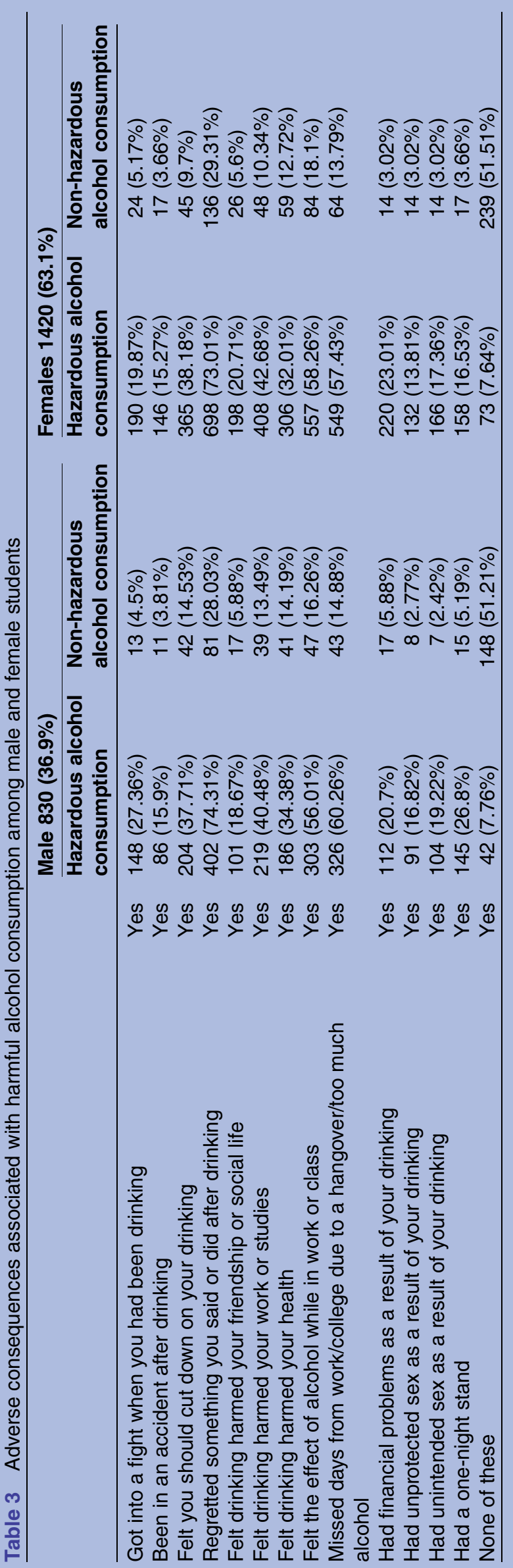

screening tool, this discrepancy between males (82\%) and females $(71 \%)$ was observed. ${ }^{24}$ Thus, the current findings of no gender gap in the prevalence of HAC is noteworthy and of particular concern given women's increased innate susceptibility to the harmful effects of alcohol. It is unclear whether this narrowing of the gender gap reflects changing cultural norms or has arisen as a direct consequence of alcohol marketing targeting young women.

The current research suggests that the prevalence of alcohol consumption in Irish university students (based on self-report) is broadly similar to levels observed in British students using the AUDIT scale ${ }^{7}$ but significantly higher than those observed in the USA. ${ }^{6}$ A large proportion of students $(31.7 \%)$ felt their drinking harmed their work or studies. The latter findings are similar to those from the Harvard College Alcohol Study where one-third of students had missed class during the last year due to their alcohol consumption. ${ }^{22}$ In other studies of alcohol consumption in university students, adverse consequences from alcohol consumption range in severity from violence and physical harm ${ }^{10}$ to unplanned and unintended sexual intercourse, ${ }^{38}$ broadly similar to those reported in this study.

The current research found that HAC was associated with smoking, an increasing number of sexual partners and illicit drug use. This study confirms previous research by Harrison $e t a \hat{l}^{39}$ who stated that smoking is associated with hazardous drinking in young adults. In relation to the sexual health of university students, previous research reports that $70 \%$ are sexually active. ${ }^{40}$ Previously, the Harvard College Alcohol Study illustrated that the reporting of unplanned sexual activity increased from $8 \%$ among non-binge drinkers, $22 \%$ among occasional binge drinkers (six or more standard drinks in one drinking occasion) to $42 \%$ among frequent binge drinkers. ${ }^{41}$ Those reporting unplanned sexual activity are also less likely to use protection. ${ }^{42}$ Coupled with high rates of short-term or casual sexual partnerships and reported low levels of sexual health knowledge, hazardous alcohol consumers are at higher risk of unintended pregnancy or contracting a sexually transmitted infection. ${ }^{43}$ Similarly, the literature shows a high prevalence of illicit drug use among university students. Previously, Chiauzzi et at $t^{44}$ reported that over $20 \%$ of the student population were found to be part of a group categorised by high-risk drinking and high prevalence of illicit drug use. The current research complements these findings, highlighting the association between alcohol and a 12-month prevalence of illicit drug use and the growing need to tackle these issues concurrently.

\section{STRENGTHS AND WEAKNESSES}

This work can be readily replicated in other universities worldwide. We used a standard, internationally recognised screening tool for HAC. PPS sampling strategy was employed to ensure that all students, regardless of 
degree course, had an equal opportunity of being included in the study. The demographics of study participants were broadly similar to those of the wider institution in relation to course of study and gender.

The overall response rate, defined in terms of students registered for specific modules, was $51 \%$. Although the response rate was low, it is similar to that achieved in major national ${ }^{10}$ and international research ${ }^{45}$ of student alcohol consumption. While this falls short of the desired rate of at least $70 \%$ in health and well-being surveys, the study provides important policy relevant data. We have no reason to believe that the nonrespondents to this survey, who were absent from class on the day of sampling, are drinking at less hazardous levels. There was over-representation of first years and under-representation of fourth years. As the prevalence of HAC was higher in fourth year students than first year students, this imbalance in sampling is likely to have led to an underestimation of overall prevalence of HAC. Thus, this study may be regarded as reporting the lower bound estimates of HAC in Irish university students. This pattern of alcohol consumption is not unique to this university, which in recent years has developed a campus-wide health promoting university initiative with a significant focus and dedicated resources centred on the problem of excessive alcohol consumption. ${ }^{46}$

\section{CONCLUSION}

HAC continues to be a public health issue in Irish university students, both in terms of immediate adverse consequences and long-term risks to physical, mental and social health and well-being. Currently, the Irish state is at a decision point with regard to policies on the promotion and marketing of alcohol. The findings from this study highlight the need for effective public policy measures in response to this issue such as a minimum unit price for alcohol and a ban on sports sponsorship.

\section{Twitter Follow Martin Davoren at @martindavoren}

Contributors MPD designed the study, analysed the data, and drafted and edited the manuscript. FS was involved in the design and conception, statistical support, drafting and editing of the manuscript. MB was involved in the design and conception of the study, as well as the drafting and editing of the manuscript. IJP was involved in the design and conception of the study, statistical support, as well as the drafting and editing of the manuscript and overall supervision of the project. All authors gave full approval of the version to be published.

Funding This research received no specific grant from any funding agency in the public, commercial or not-for-profit sectors.

Competing interests None.

Ethics approval The Clinical Research Ethics Committee, University College Cork, Ireland granted ethical approval for this research.

Provenance and peer review Not commissioned; externally peer reviewed.

Data sharing statement No additional data are available.

Open Access This is an Open Access article distributed in accordance with the Creative Commons Attribution Non Commercial (CC BY-NC 4.0) license, which permits others to distribute, remix, adapt, build upon this work non- commercially, and license their derivative works on different terms, provided the original work is properly cited and the use is non-commercial. See: http:// creativecommons.org/licenses/by-nc/4.0/

\section{REFERENCES}

1. Babor T, Caetano R, Casswell S, et al. Alcohol no ordinary commodity-research and public policy. 2nd edn. Oxford University Press, 2010.

2. Eurobarometer. EU citizens' attitudes towards alcohol. Brussels: European Commission, 2010.

3. Leifman H. Six-Country Survey of the European Comparative Alcohol Study: comparing patterns and assessing validity. Contemp Drug Probs 2002;29:477.

4. Morgan K, McGee H, Dicker P, et al. SLÁN 2007: Survey of Lifestyle, Attitudes and Nutrition in Ireland. Alcohol use in Ireland: a profile of drinking patterns and alcohol-related harm from SLÁN 2007. In: SLÁN 2007. Dublin: Department of Health and Children, 2009.

5. Organisation for Economic Co-operation and Development (OECD). OECD factbook 2013: economic, environmental and social statistics. OECD Publishing, 2013.

6. Johnston LD, O'Malley PM, Bachman JG, et al. Monitoring the future: national survey results on drug use, 1975-2009. Volume II: college students and adults ages 19-50. NIH Publication No. 10-7585. National Institute on Drug Abuse (NIDA), 2010.

7. Heather N, Partington S, Partington E, et al. Alcohol use disorders and hazardous drinking among undergraduates at English universities. Alcohol Alcohol 2011;46:270-7.

8. Health Research Board. Alcohol Diary Study 2013: technical report. MRBI I, 2014.

9. Hope A. Alcohol-related harm in Ireland. Dublin: Health Service Executive-Alcohol Implementation Group, 2008.

10. Hope A, Dring C, Dring J. College lifestyle and attitudinal national (CLAN) survey. The health of Irish students. Dublin: Health Service Executive, 2005.

11. Babor TF, Higgins-Biddle JC, Saunders JB, et al. The alcohol use disorders identification test: guidelines for use in primary care. In: The Alcohol Use Disorders Identification Test: Guidelines for Use in Primary Care. 2nd edn. Geneva, Switzerland: World Health Organization, 2001:5. http://whqlibdoc.who.int/hq/2001/who_ msd msb 01.6a.pdf

12. Kypri K, Cronin M, Wright CS. Do university students drink more hazardously than their non-student peers? Addiction 2005;100:713-14.

13. Murphy F, Murphy M. The use of social marketing messages to reduce binge drinking among Irish third level female students. Academic Public Administration Studies Archive-APAS, 2010.

14. McCabe SE. Gender differences in collegiate risk factors for heavy episodic drinking. J Stud Alcohol Drugs 2002;63:49.

15. Webb E, Ashton C, Kelly $P$, et al. Alcohol and drug use in UK university students. Lancet 1996;348:922-5.

16. Wicki M, Kuntsche E, Gmel G. Drinking at European universities? A review of students' alcohol use. Addict Behav 2010;35:913-24.

17. Schulte MT, Ramo D, Brown SA. Gender differences in factors influencing alcohol use and drinking progression among adolescents. Clin Psychol Rev 2009;29:535.

18. Harrell ZA, Karim NM. Is gender relevant only for problem alcohol behaviors? An examination of correlates of alcohol use among college students. Addict Behav 2008;33:359-65.

19. Nolen-Hoeksema S. Gender differences in risk factors and consequences for alcohol use and problems. Clin Psychol Rev 2004;24:981-1010.

20. O'Malley PM, Johnston LD. Epidemiology of alcohol and other drug use among American college students. J Stud Alcohol Drugs 2002; (14):23.

21. Kypri K, Paschall MJ, Langley J, et al. Drinking and alcohol-related harm among New Zealand university students: findings from a national web-based survey. Alcohol Clin Exp Res 2009;33:307-14.

22. Perkins $\mathrm{H}$. Surveying the damage: a review of research on consequences of alcohol misuse in college populations. J Stud Alcohol Drugs 2002;(14):91.

23. Hoeppner BB, Paskausky AL, Jackson KM, et al. Sex differences in college student adherence to NIAAA drinking guidelines. Alcohol Clin Exp Res 2013;37:1779-86.

24. McCarthy T. Campus initiatives and student consumption of alcohol at University College Cork 2009-2010: improving student health. Cork: University College Cork, 2010.

25. Kelly TM, Donovan JE, Chung T, et al. Brief screens for detecting alcohol use disorder among 18-20 year old young adults in emergency departments: comparing AUDIT-C, CRAFFT, 
RAPS4-QF, FAST, RUFT-Cut, and DSM-IV 2-Item Scale. Addict Behav 2009;34:668-74.

26. Tennant R, Hiller L, Fishwick R, et al. The Warwick-Edinburgh mental well-being scale (WEMWBS): development and UK validation. Health Qual Life Outcomes 2007:5:63.

27. IPAQ Research Committee. Guidelines for data processing and analysis of the International Physical Activity Questionnaire (IPAQ)short and long forms. Retrieved September 2005;17:2008.

28. Behavioral Risk Factor Surveillance System. http://www.cdc.gov/ brfss/

29. Department of Health \& Children. Survey of Lifestyle, Attitudes and Nutrition in Ireland. Department of Health, 2007.

30. Lee PH, Macfarlane DJ, Lam T, et al. Validity of the international physical activity questionnaire short form (IPAQ-SF): a systematic review. Int J Behav Nutr Phys Act 2011;8:115.

31. Miller JW, Naimi TS, Brewer RD, et al. Binge drinking and associated health risk behaviors among high school students. Pediatrics 2007:119:76-85.

32. Haug S, Ulbricht S, Hanke M, et al. Overestimation of drinking norms and its association with alcohol consumption in apprentices. Alcohol Alcohol 2011;46:204-9.

33. Comasco E, Berglund K, Oreland L, et al. Why do adolescents drink? Motivational patterns related to alcohol consumption and alcohol-related problems. Subst Use Misuse 2010;45:1589-604.

34. Braunholtz S, Davidson S, Myant K, et al. Well? What do you think? (2006): the third national Scottish survey of public attitudes to mental health, mental wellbeing and mental health problems. Scottish Government, 2007.

35. Davoren MP, Fitzgerald E, Shiely F, et al. Positive mental health and well-being among a third level student population. PLOS ONE 2013;8:e74921.

36. Livingston M. Measuring risky drinking: an examination of the validity of different episodic drinking thresholds in predicting alcohol-related harms. Centre for Alcohol Policy Research, 2013.
37. Wechsler $\mathrm{H}$, Lee JE, Kuo M, et al. Trends in college binge drinking during a period of increased prevention efforts: findings from 4 Harvard School of Public Health College Alcohol Study surveys: 1993-2001. J Am Coll Health 2002;50:203-17.

38. Poulin C, Graham L. The association between substance use, unplanned sexual intercourse and other sexual behaviours among adolescent students. Addiction 2001;96:607-21.

39. Harrison EL, Desai RA, McKee SA. Nondaily smoking and alcohol use, hazardous drinking, and alcohol diagnoses among young adults: findings from the NESARC. Alcohol Clin Exp Res 2008;32:2081-7.

40. Scott-Sheldon LA, Carey MP, Carey KB. Alcohol and risky sexual behavior among heavy drinking college students. AIDS Behav 2010;14:845-53.

41. Wechsler $\mathrm{H}$, Nelson TF. Binge drinking and the American college student: what's five drinks? Psychol Addict Behav 2001;15:287-91.

42. Klein W, Geaghan T, MacDonald T. Unplanned sexual activity as a consequence of alcohol use: a prospective study of risk perceptions and alcohol use among college freshmen. J Am Coll Health 2007:56:317-23.

43. Agius P, Taft A, Hemphill S, et al. Excessive alcohol use and its association with risky sexual behaviour: a cross-sectional analysis of data from Victorian secondary school students. Aust N Z J Public Health 2013;37:76-82.

44. Chiauzzi E, Dasmahapatra P, Black RA. Risk Behaviors and Drug Use: A Latent Class Analysis of Heavy Episodic Drinking in First-Year College Students. 2013.

45. Kuo M, Adlaf EM, Lee $\mathrm{H}$, et al. More Canadian students drink but American students drink more: comparing college alcohol use in two countries. Addiction 2002;97:1583-92.

46. University College Cork. Award for University College Corks approach to alcohol. University College Cork News: University College Cork, 2013. 